Cita bibliográfica: Martí Ciriquián, P., Nolasco-Cirugeda, A., y Serrano-Estrada, L. (2018). Estrategias de ocupación territorial en áreas turísticas consolidadas de la Costa Blanca (España). Boletín de la Asociación de Geógrafos Españoles, 76, 430-454. doi: 10.21138/bage.2529

\title{
Estrategias de ocupación territorial en áreas turísticas consolidadas de la Costa Blanca (España)
}

\author{
Land occupation strategies \\ in the Costa Blanca's consolidated tourist areas (Spain)
}

\author{
Pablo Martí Ciriquián \\ pablo.marti@ua.es \\ Almudena Nolasco-Cirugeda \\ almudena.nolasco@ua.es \\ Leticia Serrano-Estrada \\ leticia.serrano@ua.es \\ Departamento de Edificación y Urbanismo \\ Universidad de Alicante (España)
}

\section{Resumen}

La Costa Blanca (España) es uno de los destinos turísticos más relevantes de la costa mediterránea. La importante transformación urbana experimentada por la intensa demanda turística invita a estudiar cuáles son las estrategias de ocupación de suelo y los patrones de organización espacial que configuran estos asentamientos turísticos. Se estudian tres casos representativos -Dénia, Benidorm y Torrevieja - donde se relaciona el turismo de masas con las morfologías de tejido urbano continuo y el turismo residencial y vacacional con las morfologías de tejido urbano discontinuo.

Palabras clave: organización espacial; ocupación del suelo; actividad turística; Costa Blanca. 


\begin{abstract}
The Costa Blanca, Spain, one of the most important destinations in the Mediterranean coast, has undergone major transformations by tourist demand. This invites further study on how tourismoriented settlements are shaped in terms of land use and spatial organization patterns. Three municipalities were analysed -Dénia, Benidorm and Torrevieja- and different land occupation strategies were identified and associated to different types of tourism: continuous urban patterns are found in mass tourism areas whereas discontinuous patterns are related to residential and vacation tourism areas.
\end{abstract}

Key words: spatial organization; land use; tourism; Costa Blanca.

\title{
1 Introducción
}

La costa mediterránea española se ha consolidado como uno de los destinos turísticos más relevantes del sur de Europa. La evolución de la oferta vacacional en este ámbito - desde el turista chárter que viajaba con un paquete vacacional cerrado, hasta el reciente turista low cost que contrata productos y servicios turísticos, por su cuenta y a bajo precio, en internet (Ivars y Menor, 2008; Pié, 2013; Vera e Ivars, 2009) - ha influido en la transformación de las ciudades y la configuración de su actual estructura territorial.

Concretamente, la Costa Blanca - denominación de la marca turística utilizada para referirse a la provincia de Alicante- (Figura 1) ha experimentado durante las últimas décadas tanto un considerable crecimiento anual del número de visitantes como un importante incremento de suelo urbanizado (Domínguez et al., 2016; Jiménez, 2006; Martí y Nolasco-Cirugeda, 2012). La provincia de Alicante es la provincia más meridional de las tres que conforman la Comunidad Valenciana y su litoral abarca desde el municipio de Dénia (Norte) hasta Pilar de la Horadada (Sur), ocupando una franja costera de $244 \mathrm{Km}$ lineales en la parte central del arco Mediterráneo español. Precisamente, este espacio litoral condensa diversos casos muy representativos de la dinámica turística en áreas costeras.

Así, el litoral de la Costa Blanca ejemplifica el proceso de urbanización del Mediterráneo español donde la influencia del desarrollo turístico ha sido determinante. Turismo, planeamiento urbanístico y urbanización se han desarrollado paralelamente en este ámbito geográfico. Tal y como afirma Mantecón (2008, p. 89) "si la configuración del paisaje urbano de las ciudades situadas a orillas del Mediterráneo español ha sido determinada de forma decisiva por la dinámica turística, ésta ha sido a su vez integrada en la lógica urbanística de los tiempos modernos" que, en la mayoría de los casos no ha recurrido a una adecuada planificación y ha confundido el significado de desarrollo turístico con otros tipos de desarrollo: inmobiliario, hotelero e, incluso, de otras actividades económicas específicas. 


\section{Figura 1. La Costa Blanca en el mediterráneo español}

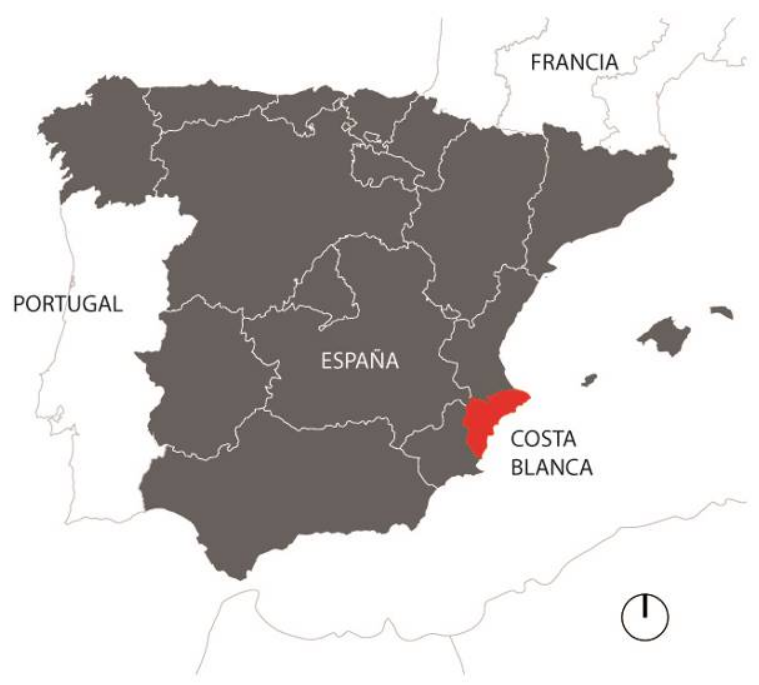

Fuente: elaboración propia

En este contexto, el motor económico del turismo ha dirigido las economías de buena parte de los municipios de esta parte del litoral, cambiando por completo muchas de las cualidades de su estructura social tradicional (Mantecón, 2008, 2016), pero también produciendo una importante transformación territorial, aspecto clave para entender el desarrollo de las actividades turísticas y sus impactos en el territorio (Hernández, 2013; Martí y Nolasco-Cirugeda, 2016).

En este sentido, la alta demanda turística de alojamiento y equipamientos para el ocio ha condicionado el desarrollo de las ciudades en este espacio litoral que se ha construido formando enclaves de carácter más o menos urbano (Vera, 2005).

El papel del planeamiento urbanístico en el desarrollo del turismo litoral ha pasado por diversas etapas a lo largo de las últimas décadas. Inicialmente, la planificación del crecimiento urbano condicionó el desarrollo de la actividad turística en el litoral alicantino que, a su vez, se materializó en distintas formas y con características diferenciales muy representativas de los asentamientos turísticos de la costa mediterránea española. Sin embargo, las condiciones impuestas por el planeamiento reciente no han regulado suficientemente los crecimientos turísticos en algunos municipios y se han generado extensas áreas urbanizadas en entornos litorales, cuya estructura difiere sustancialmente respecto a la de los modelos tradicionales de ocupación de la ciudad mediterránea -compacta y compleja- (Rueda, 1997). Por tanto, aunque la planificación urbanística municipal puede ser una herramienta adecuada para proyectar los nuevos desarrollos turísticos, su aplicación ha demostrado que resultan contadas las ocasiones en que se han establecido límites precisos al crecimiento turístico en el ámbito de la Costa Blanca. Además, en los últimos tiempos, 
estos crecimientos se han caracterizado por el consumo casi indiscriminado de suelo para la ubicación de nuevos desarrollos.

En este contexto, el objetivo de este trabajo se centra en analizar las características de los modelos urbanos desarrollados en relación con los distintos tipos de turismo de los destinos litorales de la Costa Blanca. Para ello, a través de tres ejemplos diferentes (Dénia, Benidorm y Torrevieja) se identifican los siguientes aspectos: en primer lugar, la proporción de suelo ocupado por la actividad turística en relación con la superficie total del término municipal; en segundo lugar, las características de estos espacios turísticos; y en tercer lugar, se establecen relaciones entre las diferentes ocupaciones urbanas y territoriales -tejidos urbanos continuos y discontinuos- y las diversas características de la oferta turística y sus destinatarios -turismo de masas, residencial y vacacional-.

\subsection{El crecimiento urbano: evidencias de transformación en el territorio litoral motivado por la actividad turística}

En el contexto estatal español, la provincia de Alicante y, concretamente, su litoral ha experimentado la mayor transformación global del suelo del arco Mediterráneo. Los datos del estudio Cambios en la Ocupación del Suelo del Observatorio de la Sostenibilidad en España, indican que, considerando la franja de 0 a 2 kilómetros, Alicante es la tercera provincia española en la que mayor artificialización de suelo se ha producido y que, en la franja entre 2 y 5 kilómetros, es la primera con un incremento del 92,2 \% en la superficie de suelo artificial en el periodo 1987-2000 (Tabla 1 y Figura 2). El dato es incluso más impactante al observar que el resto de provincias costeras españolas -incluyendo las costas mediterráneas, atlántica y los archipiélagos- encuentran su crecimiento en esta franja por debajo del $40 \%$. Este fuerte incremento en la ocupación del suelo, que se produce en el denominado "ciclo hiperurbanizador" (Gaja, 2008; Membrado, 2015), está determinado, en gran parte, por la importancia del turismo como motor económico de muchas localidades tal y como sugieren algunos estudios a nivel estatal (Burriel de Orueta, 2008; Jiménez, 2006) y a nivel de las comarcas litorales de la Costa Blanca (Martí y Nolasco-Cirugeda, 2012). 
Tabla 1. Superficie artificializada según franjas paralelas a la costa entre 1987 y 2000

\begin{tabular}{|c|c|c|c|c|c|c|c|c|}
\hline \multirow[b]{2}{*}{ Costas españolas } & \multicolumn{4}{|c|}{ Franja de 0 a 2 kilómetros } & \multicolumn{4}{|c|}{ Franja de 2 a 5 kilómetros } \\
\hline & $\begin{array}{l}\text { Superficie } \\
\text { total (ha) }\end{array}$ & $\begin{array}{l}\text { Superficie } \\
\text { artificial en } \\
\text { el año } \\
2000 \text { (ha) }\end{array}$ & $\begin{array}{c}\text { Porcentaje } \\
\text { de } \\
\text { ocupación } \\
\text { artificial en } \\
2000 \\
\text { sobre el } \\
\text { total (\%) }\end{array}$ & $\begin{array}{c}\text { Incremento } \\
\text { de la } \\
\text { superficie } \\
\text { artificial } \\
1987-2000 \\
(\%)\end{array}$ & $\begin{array}{l}\text { Superficie } \\
\text { total (ha) }\end{array}$ & $\begin{array}{l}\text { Superficie } \\
\text { artificial en } \\
\text { el año } \\
2000 \text { (ha) }\end{array}$ & $\begin{array}{c}\text { Porcentaje } \\
\text { de } \\
\text { ocupación } \\
\text { artificial en } \\
2000 \\
\text { sobre el } \\
\text { total (\%) }\end{array}$ & $\begin{array}{l}\text { Incremento } \\
\text { de la } \\
\text { superficie } \\
\text { artificial } \\
1987-2000 \\
(\%)\end{array}$ \\
\hline $\begin{array}{l}\text { TOTAL COSTAA } \\
\text { MEDITERRÁNEA }\end{array}$ & 278841 & 73823 & 26,50 & 19,10 & 395953 & 47569 & 12,00 & 28,70 \\
\hline ALICANTE & 33414 & 12629 & 37,80 & 40,80 & 51610 & 8047 & 15,60 & 92,20 \\
\hline $\begin{array}{l}\text { TOTAL COSTA } \\
\text { ATLÁNTICA SUR }\end{array}$ & 64431 & 12316 & 19,10 & 19,80 & 91456 & 5444 & 21,80 & 6,00 \\
\hline $\begin{array}{l}\text { TOTAL } \\
\text { ARCHIPIÉLAGOS }\end{array}$ & 337119 & 36613 & 10,90 & 15,50 & 357290 & 15537 & 4,30 & 17,90 \\
\hline $\begin{array}{l}\text { TOTAL COSTA } \\
\text { ATLÁNTICO- } \\
\text { CANTÁBRICA }\end{array}$ & 276727 & 37596 & 13,60 & 7,10 & 321416 & 16303 & 5,10 & 20,80 \\
\hline
\end{tabular}

Fuente: elaboración propia a partir de Jiménez (2006)

Figura 2. Evolución de la ocupación de suelo en la provincia de Alicante 1990-2006

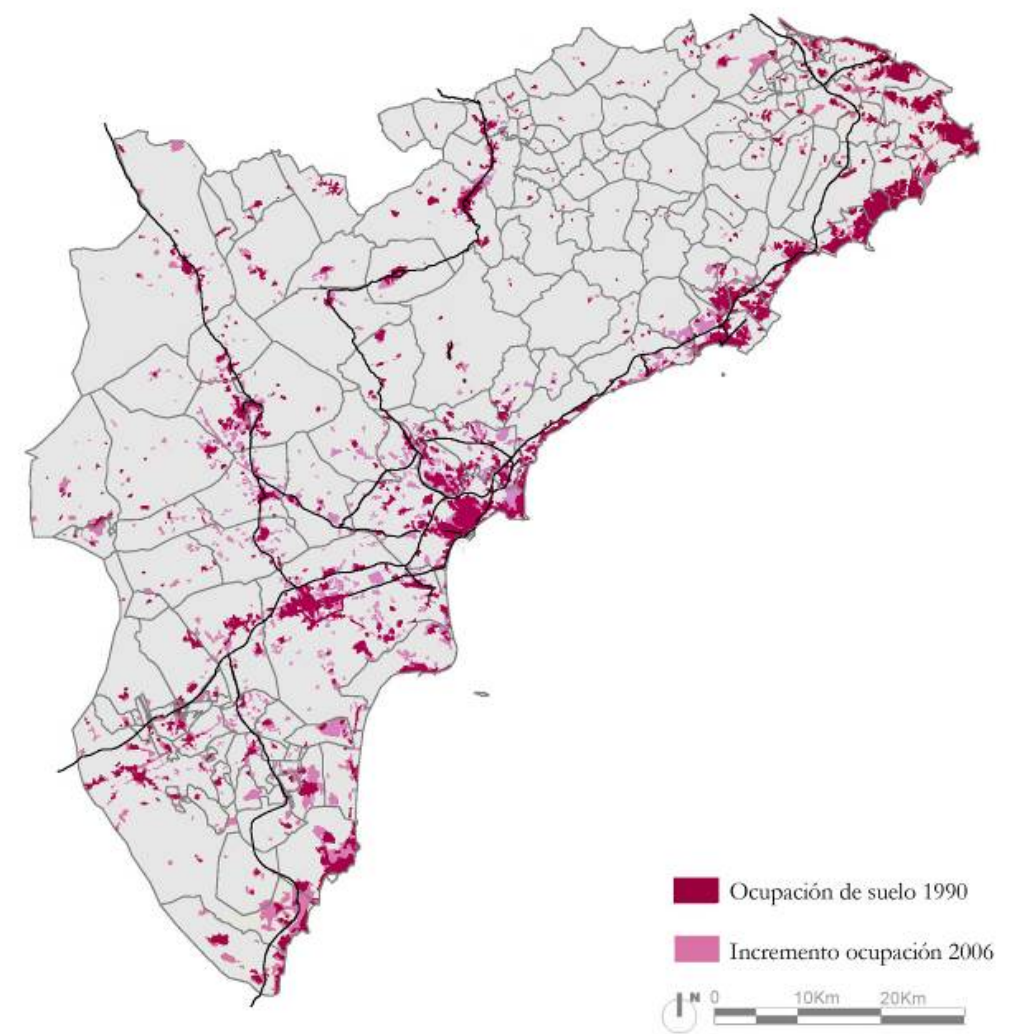

Fuente: elaboración propia a partir de datos Corine Land Cover 
En los años sesenta y setenta, los asentamientos turísticos se disponen a lo largo de la costa, configurando un continuo lineal surgido de forma un tanto espontánea en emplazamientos próximos a los núcleos prexistentes o en continuidad con ellos, en los que se construyen singulares equipamientos para el alojamiento y el ocio (Martínez-Medina, 2016). La progresiva colmatación del frente litoral obliga, con el tiempo, a la localización del espacio urbano turístico hacia el interior donde el atractivo se asocia el disfrute de vistas privilegiadas o a la proximidad a otros espacios naturales (Figura 3).

Además, la localización de nuevas actuaciones turístico-inmobiliarias en municipios del interior es una alternativa a la saturación de la primera línea de costa y el consecuente encarecimiento del precio del suelo. Por tanto, los nuevos asentamientos promocionan su valor paisajístico y una menor masificación a precios reducidos, aunque manteniendo como propia la imagen de la costa y las ciudades del litoral (Vera et al., 2011).

Figura 3. Vista de la ocupación de urbanizaciones turísticas en primera línea de costa (Altea Hills y peñón de Ifach en Calpe)

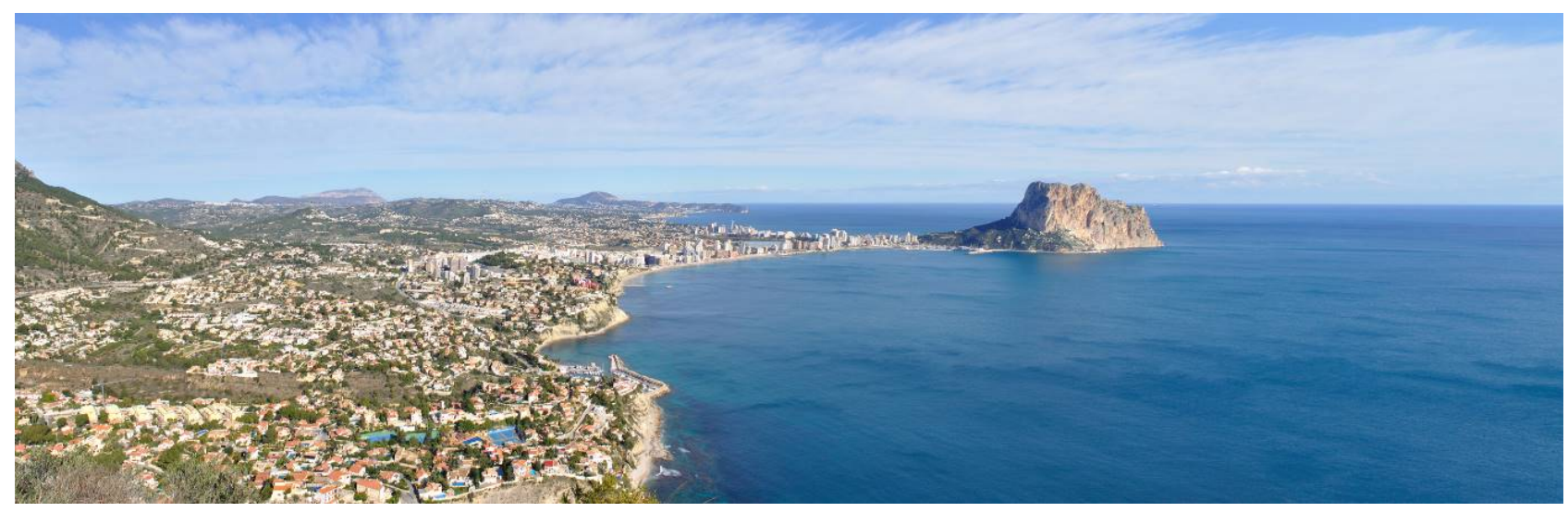

Fuente: elaboración propia

\subsection{Las formas de ocupación recientes del espacio litoral de la Costa Blanca}

El estudio de las formas de ocupación del territorio en relación con el fenómeno turístico resulta de interés por el impacto que las infraestructuras para el alojamiento y el ocio tienen en la estructura funcional del territorio. Sus implicaciones territoriales afectan a cuestiones morfológicas y funcionales como la movilidad, la densidad de población y la distribución de usos en el espacio, entre otras.

Actualmente, la urbanización desarrollada para alojar la actividad turística se diferencia de las utilizadas anteriormente en el modelo de asentamiento. La forma de consumir el territorio por parte de los desarrollos urbanos actuales es radicalmente distinta como sucede, por ejemplo, con las nuevas urbanizaciones de baja densidad aisladas en el territorio o las asociadas a campos de golf. 
En el caso de la Costa Blanca, se reconocen fundamentalmente dos estrategias en la construcción del espacio turístico. El primer tipo de ocupación corresponde a los desarrollos urbanos dispersos (Figura 4) que se utilizan, frecuentemente, para el alojamiento turístico residencial, en contraposición a la forma tradicional de ocupación del territorio de la ciudad mediterránea (Rueda, 1997). Esta tipología de alojamiento es la preferida por aquellos visitantes que "llegan para quedarse" (Huete, 2009), atraídos por el sol, las playas y una climatología favorable durante gran parte del año.

La apropiación de modelos propios del urbanismo anglosajón como respuesta a las necesidades alojativas del denominado turismo residencial (Huete y Mantecón, 2011) se ha convertido en habitual. Además, las segundas residencias en la costa y en el interior han transformado paisajes tradicionales como el de la Huerta de la Vega Baja del río Segura (García-Mayor, 2017) que, utilizando tipologías de baja densidad en entornos pseudo-urbanos, buscan aproximarse a la naturaleza; disfrutar del paisaje, la climatología y el entorno, que son, en esencia, los atractivos fundamentales del turismo litoral.

\section{Figura 4. Urbanizaciones turísticas en San Fulgencio (la Marina-Oasis), municipio situado en el espacio prelitoral}

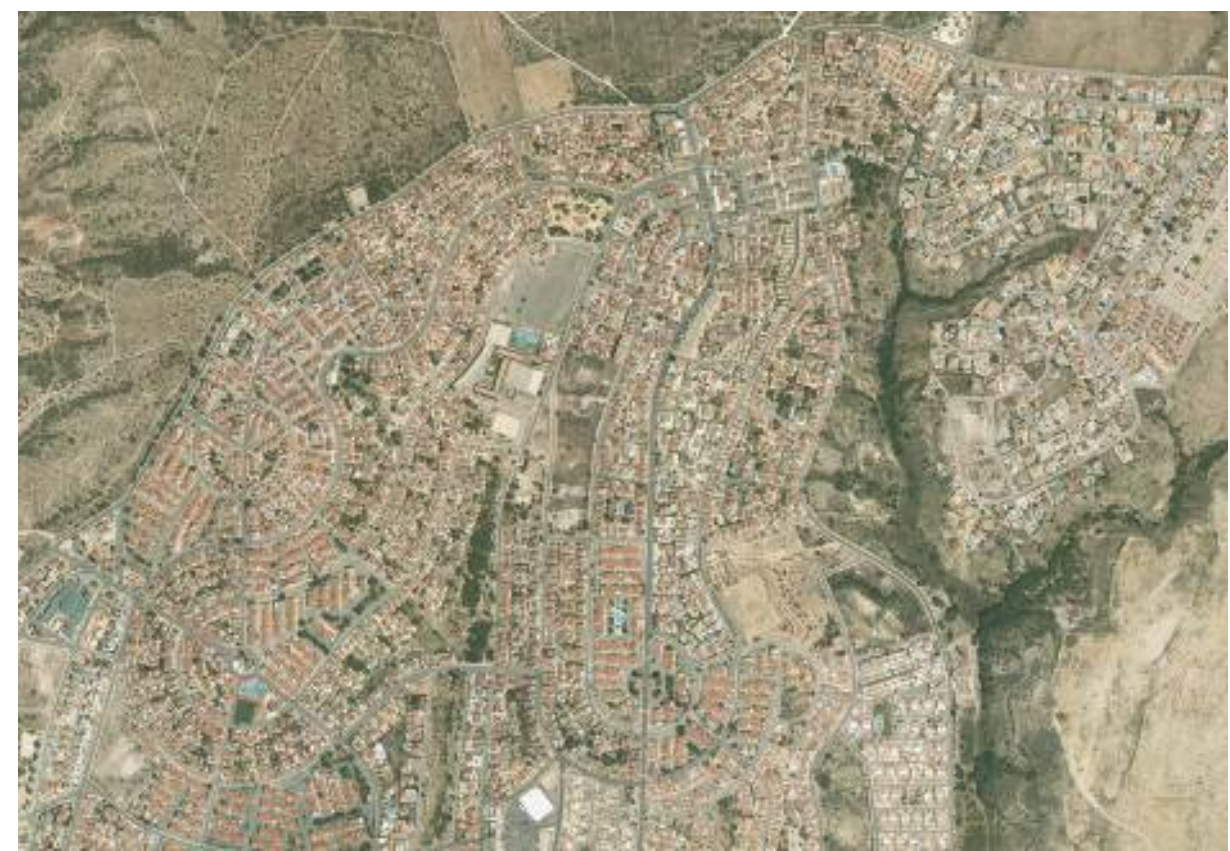

Fuente: fotografía aérea Plan Nacional de Ortofotografía Aérea (PNOA) (Instituto Geográfico Nacional y Ministerio de Fomento, 2015)

La segunda estrategia de implantación territorial se materializa a través de modelos que se desarrollan en altura junto a la línea de costa (Figura 5) permitiendo localizar, en primera línea de mar, a un mayor número de visitantes y consiguiendo aproximar las funciones y comodidades urbanas al atractivo entorno natural. Estos modelos, que frecuentemente se construyen con carácter 
rotacional, son los preferidos para el alojamiento del turismo de masas. La construcción de apartamentos turísticos y hoteles en edificios en altura influye en aspectos territoriales que abarcan, desde la eficiencia en la ocupación del territorio, hasta el negativo impacto visual que producen en entornos paisajísticos de gran valor.

Si bien no existen municipios que hayan desarrollado un único modelo de ocupación, sí es cierto que los municipios intentan alcanzar cierto grado de especialización para satisfacer las demandas de determinados tipos de turista (Vera et al., 2011). En este sentido, la concentración de esfuerzos para satisfacer un sector concreto mejora la calidad de la experiencia turística de forma sustancial. Es frecuente observar cómo cada municipio desarrolla nuevas áreas urbanas según el tipo de turista al que quiere atraer, desarrollando diversas estrategias de especialización y diversificación para mantener su competitividad. Así, aparecen espacios turísticos ex novo -o de nueva plantacreados al margen de la estructura territorial, urbana y turística prexistente que buscan la reformulación del modelo turístico de sol y playa implantado. Como indica Vera (2011, p. 89), se diseñan complejos que funcionan de forma totalmente aislada e independiente "constituyendo el principio y el fin del escenario turístico" o se transforman algunos espacios urbanos para convertirlos en producto turístico, llevando a cabo remodelaciones de sus espacios públicos más relevantes (Martí et al., 2017b), como los paseos marítimos, o incorporando puertos deportivos en antiguos puertos pesqueros.

Por tanto, resulta necesaria una planificación territorial y urbana que considere las necesidades de la demanda turística y, a su vez, sea capaz de construir modelos de ocupación adecuados; es decir, que atienda no sólo a dicha demanda, sino también a la estructura territorial. Actualmente se constata cómo los destinos turísticos maduros del litoral -denominados así por su alto grado de consolidación- han evolucionado hasta convertirse en enclaves urbanos muy complejos, difíciles de articular con la existente estructura territorial.

Por todos los motivos expuestos, resulta de interés conocer las estrategias con que se han consolidado los asentamientos turísticos en esta parte del Mediterráneo dada su importancia en el contexto geográfico europeo y la diversa casuística observada -turismo de masas, turismo residencial y turismo vacacional-. Igualmente, el conocimiento de las diferentes estrategias de ocupación permite definir e intervenir en la planificación urbano-turística actual y futura. Por ello, se estudia la ocupación actual del suelo destinada al uso turístico en el litoral de la Costa Blanca, así como su organización espacial atendiendo a las características propias de la actividad turística. 
Figura 5. Edificaciones en la primera línea de costa. Playa del Cura (Torrevieja)

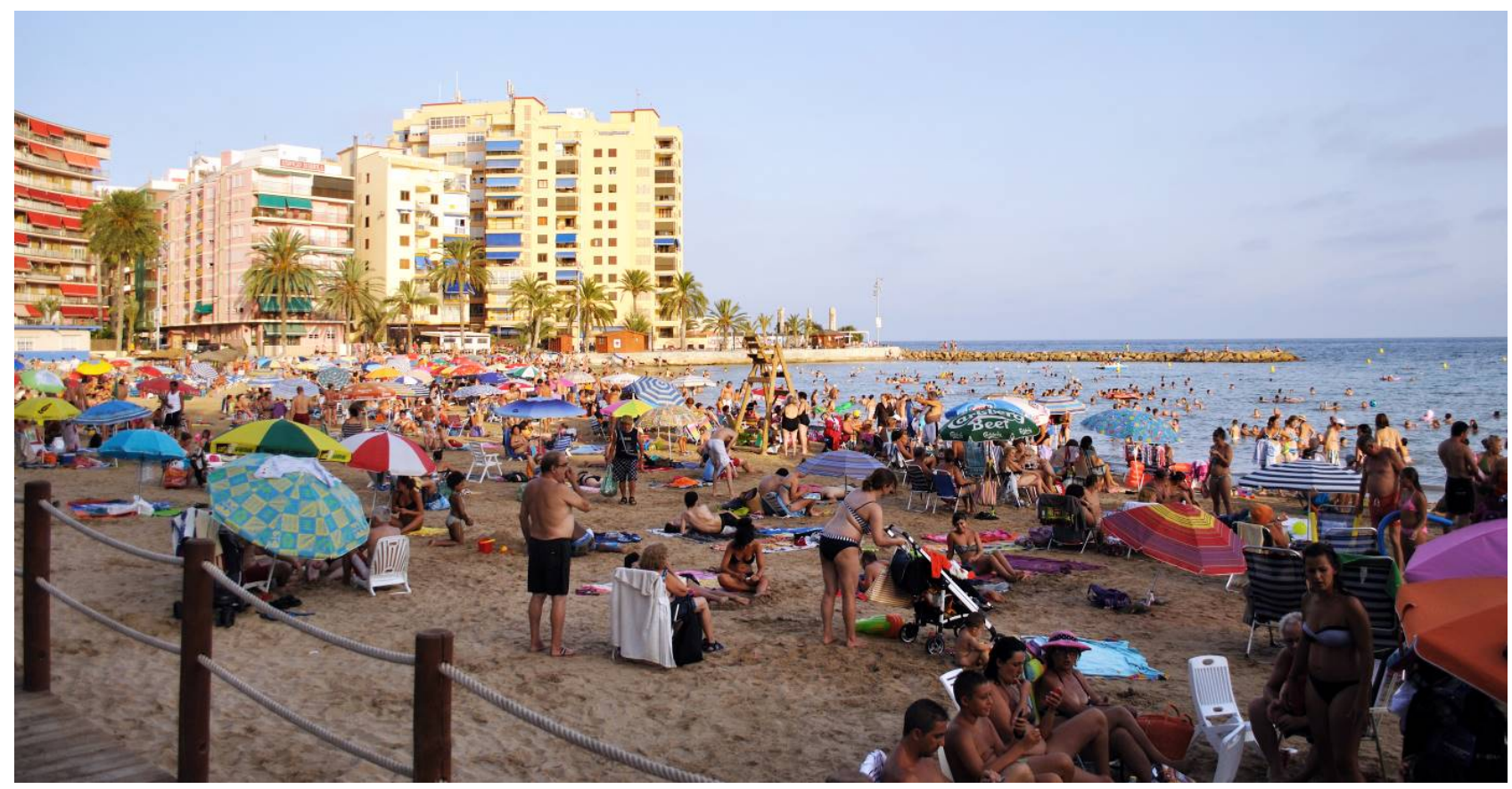

Fuente: elaboración propia

\subsection{Tipos de turismo en la Costa Blanca y sus casos representativos. Selección de casos de estudio}

La diferente oferta turística atrae a una gran variedad de visitantes a lo largo de la costa alicantina. Coincidiendo con esta diversidad, se identifican varios patrones urbanos y territoriales de ocupación que hacen un uso muy diferente de los recursos $-y$, por tanto, del territorio- para satisfacer el interés de la demanda.

Para estudiar con mayor profundidad estos procesos de especialización y diversificación en los que se relaciona la demanda turística con las formas de desarrollo urbano y ocupación territorial, se analizan tres casos de estudio que representan, a su vez, los espacios donde se desarrollan tres estrategias de oferta turística (Baños, 1999).

A partir del análisis de algunos datos característicos de los distintos tipos de turismo, incluidos en estudios previos (Huete, 2016; Vera y Díez, 2016), se seleccionan tres municipios en la Costa Blanca -Dénia, Benidorm y Torrevieja- cuyos modelos de desarrollo urbano difieren entre sí, y atraen a distintos tipos de turista. Además, estas poblaciones siguen apostando, en la actualidad, por la actividad turística como motor fundamental de sus economías. Los tres casos de estudio resultan representativos dado que constituyen una selección múltiple con valor instrumental capaz de ilustrar las estrategias de ocupación de suelo de los modelos turísticos consolidados -turismo vacacional, turismo de masas y turismo residencial, respectivamente-. Su representatividad resulta 
analítica más que estadística y se eligen por tener la capacidad de ejemplificar la diversidad de estrategias utilizadas como sistema de ocupación territorial en el contexto geográfico de estudio.

Así, la planificación regional -la Estrategia Territorial de la Comunidad Valenciana, ETCV (Consellería de Medio Ambiente Urbanismo y Vivienda, 2011) - reconoce los casos seleccionados como centros de polaridad principal en sus respectivas áreas funcionales y los considera núcleos muy importantes, no sólo en cuanto a su posición territorial y su consolidada experiencia turística, sino también en cuanto a la densidad de población que alojan -Dénia $263 \mathrm{hab} / \mathrm{Km}^{2}$, Benidorm $330,7 \mathrm{hab} / \mathrm{Km}^{2}$ y Torrevieja $408 \mathrm{hab} / \mathrm{Km}^{2}$-. Los tres son municipios costeros en los que la actividad turística comienza a desarrollarse en épocas muy tempranas (años 1950-1960) respecto a la experiencia más tardía de otras zonas; por lo que se trata de municipios en los que la experiencia turística se encuentra ampliamente consolidada. Son áreas donde el desarrollo turístico tiene un carácter muy definido, alcanzando un alto grado de especialización, y que han experimentado, no sólo un primer estadio de desarrollo, sino varias etapas de transformación. Asimismo, el turismo vacacional combina dinámicas de alojamiento hotelero con el alojamiento en segunda residencia en diversa proporción.

El carácter turístico de cada uno de los municipios seleccionados se explicita observando los datos de pernoctación y de vivienda secundaria en cada uno de ellos (Tabla 2). De este modo, Benidorm se perfila como un municipio dedicado fundamentalmente al turismo de masas rotacional por la elevada cantidad de pernoctaciones; Torrevieja mantiene un elevado número de viviendas secundarias y de potencial uso turístico (Vera y Díez, 2016) que lo definen como un destino de turismo masivo de perfil residencial (Pié y Rosa, 2013) potenciado por la industria low cost descrita en el apartado de Introducción-; y, finalmente, Dénia muestra un perfil de turismo vacacional híbrido que combina el turismo residencial con el propiamente rotacional, a la vista del porcentaje de vivienda secundaria y el número de viajeros y pernoctaciones.

Tabla 2. Datos de pernoctación y de vivienda secundaria de los casos de estudio

\begin{tabular}{|l|c|c|c|c|c|c|c|}
\hline Población & Pernoctaciones & Viajeros & $\begin{array}{c}\text { Total } \\
\text { viviendas }\end{array}$ & $\begin{array}{c}\text { Viviendas } \\
\text { principales } \\
\text { convencionales }\end{array}$ & $\begin{array}{c}\text { Viviendas } \\
\text { secundarias }\end{array}$ & $\begin{array}{c}\text { Viviendas } \\
\text { vacías }\end{array}$ & $\begin{array}{c}\text { Porcentaje } \\
\text { Vivienda } \\
\text { secundaria } \\
(\%)\end{array}$ \\
\hline Dénia & 371335 & 96388 & 43340 & 17250 & 12505 & 13585 & $28,85 \%$ \\
\hline Benidorm & 10741126 & 1881614 & 58010 & 27910 & 25130 & 4090 & $43,32 \%$ \\
\hline Torrevieja & 23224 & 7237 & 122325 & 39855 & 62585 & 19885 & $51,16 \%$ \\
\hline
\end{tabular}

Fuente: encuesta de Ocupación Hotelera (INE, 2013a) y Censo 2011 (INE, 2013b)

Además de estas consideraciones, otras cuestiones refuerzan la selección individual de estos municipios como casos de estudio, de acuerdo con la planificación de su crecimiento y cómo ésta se relaciona con la actividad turística. 
En primer lugar, el municipio de Dénia, que es destino de turistas europeos, representa el modelo turístico propio de la comarca de la Marina Alta, al norte de la provincia de Alicante. Según Vera (1987, p. 311) "se combinan las dos formas de urbanización más específicas del litoral alicantino", haciendo referencia a las tipologías de bloque de apartamentos próximas al núcleo urbano y a la edificación de baja densidad, como sucede, tanto en el área de Les Marines en la costa, como en la ladera del Montgó hacia el interior. Este es un tipo de turismo muy frecuente en la costa mediterránea española donde se alojan durante la época estival turistas provenientes de todo el norte de Europa.

En segundo lugar, Benidorm constituye el paradigma del desarrollo del turismo de masas en la Costa Blanca. La ciudad ocupa el tercer lugar en número de pernoctaciones en todo el ámbito estatal (INE, 2013a), únicamente por detrás de Madrid y Barcelona hasta 2013, y el cuarto lugar en 2014. Su planificación urbanística, alabada por unos y denostada por otros, consigue alojar a una gran cantidad de población turística en un espacio atractivo de marcado carácter urbano. Las construcciones en altura que caracterizan el modelo de ocupación de Benidorm permiten alojar una muy alta concentración de visitantes. Además, el inicio de su planificación urbanística municipal en 1956 se produce de forma paralela a los primeros signos de desarrollo turístico en España, lo que supone una importante experiencia a tener en cuenta ya que, a la vista de esta cuestión, el modelo de ocupación de la actividad turística de Benidorm ha estado dirigido por la planificación urbanística desde el inicio. Igualmente, resulta destacable el continuo interés por la reestructuración y renovación de la ciudad como destino para la mejora de su competitividad en el mercado turístico (Ivars et al., 2013; Vera et al., 2011).

En tercer y último lugar, Torrevieja, es actualmente el destino de gran cantidad de noreuropeos que buscan una segunda residencia en la costa mediterránea. A pesar de que la actividad turística empieza a desarrollarse al mismo tiempo que en el resto de casos de estudio, es en los años 80 cuando se especializa en ofrecer aquello que demanda el creciente turismo de clase media. Si hasta ese momento el turismo había estado reservado a unos pocos con alto poder adquisitivo, en esa década, se consolida la capacidad de veraneo de otros estratos sociales en España. De modo que, en Torrevieja, se apuesta por satisfacer esta nueva demanda que adquiere gran complejidad cuando la demanda internacional encuentra aquí la localización adecuada para establecer su segunda residencia. Es así como, en las últimas décadas, la creación y promoción de nuevos productos turísticos constituye una prioridad en su estrategia turística (Vera et al., 2016).

Por tanto, los espacios turísticos seleccionados como casos de estudio se consideran ejemplos completos, complejos y con alto grado de consolidación, además de representativos de las distintas formas urbanas en que se desarrolla el turismo en la costa mediterránea española, permitiendo explicar las diferentes estrategias de ocupación y organización espacial de la actividad turística. 


\section{Metodología y fuentes de información para el análisis de las diferentes estrategias}

Para analizar las diferentes estrategias de ocupación, una vez seleccionados los casos de estudio, es preciso acometer dos tareas: en primer lugar, identificar dónde se localizan las áreas urbanas turísticas en cada uno de los casos y, en segundo lugar, analizar cuantitativa y cualitativamente parámetros y aspectos que describan las características de las diferentes estrategias de ocupación identificadas.

Como primera tarea, se delimitan las áreas de suelo ocupado utilizando la cartografía elaborada por el proyecto Corine Land Cover 2006 (European Environment Agency, 2006) que permite conocer los usos del suelo y el tipo de tejidos que los conforman. A esta información base, se le superponen dos capas de datos para identificar usos propios del turismo: por un lado, las actividades deportivas, comerciales o de ocio propias de las áreas turísticas, así como complejos hoteleros, campos de golf y parques recreativos - utilizando la base de datos Winsitur (Agència Valenciana de Turisme) $-{ }^{1} y$, por otro lado, la delimitación de secciones censales con su respectivo porcentaje de vivienda secundaria - procedente del censo 2011 del Instituto Nacional de Estadística (INE, 2013b)-.

A partir de la representación de todos estos datos sobre la cartografía, se reconocen como áreas de uso fundamentalmente turístico aquellas que contienen una mayor proporción de alojamientos y usos relacionados con el ocio, así como elevados porcentajes de vivienda secundaria.

La segunda tarea consiste en el cálculo de parámetros cuantitativos -relacionados con la evaluación de la ocupación del suelo en áreas turísticas (Martí et al., 2017a) - y la descripción de características propias de cada uno de los modelos de ocupación.

En primer lugar, se calcula la proporción de suelo ocupado en relación con la superficie total del término municipal para obtener un indicador de la cantidad total de suelo que se ha urbanizado. Este valor es particularmente interesante dado que la Estrategia Territorial de la Comunidad Valenciana (Consellería de Medio Ambiente Urbanismo y Vivienda, 2011), cifra en un $10 \%$ el Índice de Máxima Ocupación de Suelo (IMOS) en cada municipio y, por tanto, los municipios que superen dicho porcentaje de ocupación en el planeamiento vigente no podrán desarrollar más superficie de la ya aprobada.

En segundo lugar, se calcula la proporción de suelo correspondiente a la superficie ocupada por áreas de uso fundamentalmente turístico -identificadas anteriormente- respecto al total ocupado.

1 Winsitur es una base de datos producto del interés de la Agència Valenciana del Turisme por difundir información detallada sobre los recursos y actividades turísticas de la Comunidad Valenciana: Hoteles, campings, restaurantes, alojamiento rural, ocio, turismo activo, etc. (Agència Valenciana del Turisme, 2014). 
Con este dato se obtiene cuánto suelo destina cada municipio al uso turístico, valor que no se calcula en ninguna figura de planeamiento puesto que no es una categoría que habitualmente se contemple en la redacción de planes urbanísticos. Además, es relevante conocer, tanto la cantidad del suelo consumido para alojar la actividad turística, como cuáles son los emplazamientos ocupados, lo que permite identificar cuáles son las mejores localizaciones para el desarrollo del uso turístico.

En tercer y último lugar, se analizan los tipos de tejido de las áreas fundamentalmente turísticas identificando las tipologías edificatorias que conforman el espacio turístico -a partir de la información catastral-, ${ }^{2}$ observando los tipos de usos y de espacios libres que se desarrollan en estas áreas y consultando la base cartográfica del proyecto Corine Land Cover 2006 para conocer la cualidad de continuidad-discontinuidad. ${ }^{3}$

Dado que los municipios seleccionados como casos de estudio se han identificado como representativos de un tipo específico de turismo, los resultados obtenidos en cada uno de los ámbitos delimitados y caracterizados permiten explicar cuáles son las estrategias de ocupación territorial de cada una de las tipologías turísticas consolidadas en la Costa Blanca.

\section{El turismo en la costa blanca: ocupación y organización espacial}

Los resultados obtenidos evidencian, tanto cuestiones comunes a los tres casos de estudio, como diferencias entre ellos. Precisamente, esas coincidencias y divergencias permiten evaluar las características comunes de los espacios turísticos, así como explicar las distintas estrategias de ocupación y organización espacial según los distintos modelos turísticos alojados. Respecto a las similitudes encontradas destacan tres aspectos.

En primer lugar, se observa que los tres casos estudiados superan en mucho (Tabla 3) el valor establecido como índice de máxima ocupación del suelo (10\%) en la Estrategia Territorial de la Comunidad Valenciana. La consolidación del $27 \%$, $38 \%$ y $42 \%$ del suelo municipal en Dénia, Benidorm y Torrevieja, respectivamente, indica una gran transformación de suelo en los territorios de la costa, por lo que la planificación futura deberá centrarse en regenerar y reconvertir el tejido consolidado, así como aprovechar los vacíos urbanos que existan en el continuo urbanizado antes de plantear nuevos crecimientos en suelos no urbanizados.

2 El Catastro es un registro administrativo que depende del Ministerio de Hacienda y Administraciones Públicas de España. Contiene la descripción de los bienes inmuebles rústicos, urbanos y de características especiales, cuya inscripción en el mismo es obligatoria y gratuita. (Dirección General del Catastro, 2015).

3 La referencia a tejido urbano continuo o tejido urbano discontinuo proviene de la traducción del nomenclator utilizado por Corine Land Cover para el reconocimiento de distintos tipos de ocupación (Steenmans et al., 2006). 
En segundo lugar, los resultados evidencian de forma rotunda cómo, independientemente del grado de ocupación del término municipal, el uso turístico es el que más superficie ocupa en todo el conjunto urbanizado pues son las áreas turísticas las que en mayor medida generan la transformación del suelo. En todos los casos estudiados, las áreas turísticas ocupan un porcentaje superior al 77 \% respecto al total de suelo ocupado (Tabla 3). Por este motivo, la planificación de la actividad turística desde el punto de vista de la planificación urbana y territorial resulta fundamental para la buena articulación de funciones en el territorio y la correcta disposición de actividades en el mismo.

En tercer lugar, se observa que el uso que más suelo consume en áreas turísticas es el residencial -tejido urbano continuo y tejido urbano discontinuo (Tabla 3) -, lo que evidencia que las políticas dirigidas a satisfacer la demanda de segunda residencia en la costa han contribuido activamente a la importante transformación territorial mencionada en el apartado de introducción. En este sentido, cómo se materializa el uso residencial -en forma de tejido continuo o discontinuo- incide directamente en la capacidad de alojar la población de un territorio. Precisamente, el análisis de este último aspecto permite observar las estrategias diferenciadas en cuanto al crecimiento y desarrollo urbano, sobresaliendo los siguientes aspectos.

Tabla 3. Ocupación del suelo en los casos de estudio según distribución de usos y tipo de área (turística o convencional)

\begin{tabular}{|c|c|c|c|c|c|c|c|}
\hline & \multicolumn{2}{|c|}{$\begin{array}{c}\text { DÉNIA } \\
\text { Destino vacacional }\end{array}$} & \multicolumn{2}{|c|}{$\begin{array}{c}\text { BENIDORM } \\
\text { Destino turismo de masas }\end{array}$} & \multicolumn{2}{|c|}{$\begin{array}{c}\text { TORREVIEJA } \\
\text { Destino turismo residencial }\end{array}$} \\
\hline & & $\begin{array}{l}\text { Área } \\
\text { turística }\end{array}$ & $\begin{array}{l}\text { Fuera de } \\
\text { área } \\
\text { turística }\end{array}$ & $\begin{array}{l}\text { Área } \\
\text { turística }\end{array}$ & $\begin{array}{l}\text { Fuera de } \\
\text { área } \\
\text { turística }\end{array}$ & $\begin{array}{l}\text { Área } \\
\text { turística }\end{array}$ & $\begin{array}{l}\text { Fuera de } \\
\text { área } \\
\text { turística }\end{array}$ \\
\hline \multirow{2}{*}{\multicolumn{2}{|c|}{$\begin{array}{l}\text { Superficie término municipal (ha) } \\
\text { Total de suelo ocupado en el término } \\
\text { municipal (ha) }\end{array}$}} & \multicolumn{2}{|c|}{6618 ha } & \multicolumn{2}{|c|}{3851 ha } & \multicolumn{2}{|c|}{7144 ha } \\
\hline & & \multicolumn{2}{|c|}{1786,29 ha (27 \%) } & \multicolumn{2}{|c|}{1480,80 ha (38 \%) } & \multicolumn{2}{|c|}{$\begin{array}{l}2122,49 \text { ha (42\% suelo sin } \\
\text { inundar) }\end{array}$} \\
\hline \multicolumn{2}{|c|}{$\begin{array}{l}\text { Suelo que ocupan las áreas turísticas en } \\
\text { el conjunto del total ocupado (ha y } \\
\text { porcentaje que representa \%) }\end{array}$} & $\begin{array}{c}1402,69 \text { ha } \\
(78,6 \%)\end{array}$ & $\begin{array}{c}383,60 \text { ha } \\
(21,4 \%)\end{array}$ & $\begin{array}{l}1151,75 \text { ha } \\
(77,8 \%)\end{array}$ & $\begin{array}{c}329,05 \text { ha } \\
(22,3 \%)\end{array}$ & $\begin{array}{c}1644,34 \text { ha } \\
(77,5 \%)\end{array}$ & $\begin{array}{c}478,15 \text { ha } \\
(22,5 \%)\end{array}$ \\
\hline \multirow{9}{*}{ 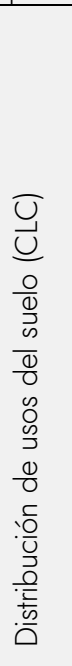 } & Tejido urbano continuo & $\begin{array}{c}\text { 17.62 ha } \\
(1,0 \%)\end{array}$ & $\begin{array}{c}120.26 \text { ha } \\
(6.7 \%)\end{array}$ & $\begin{array}{c}348,47 \text { ha } \\
(23,5 \%)\end{array}$ & $\begin{array}{c}172,46 \text { ha } \\
(11,6 \%)\end{array}$ & $\begin{array}{l}9,69 \text { ha } \\
(0,5 \%) \\
\end{array}$ & $\begin{array}{c}281,88 \text { ha } \\
(13,3 \%)\end{array}$ \\
\hline & Tejido urbano discontinuo & $\begin{array}{c}1274.99 \mathrm{ha} \\
(71,4 \%)\end{array}$ & $\begin{array}{c}100.05 \mathrm{ha} \\
(5.6 \%)\end{array}$ & $\begin{array}{c}349,92 \mathrm{ha} \\
(23,6 \%)\end{array}$ & $\begin{array}{l}0,15 \text { ha } \\
(0 \%)\end{array}$ & $\begin{array}{c}1317,69 \text { ha } \\
(62,1 \%)\end{array}$ & $\begin{array}{l}0,12 \text { ha } \\
(0 \%)\end{array}$ \\
\hline & $\begin{array}{l}\text { Instalaciones deportivas y } \\
\text { recreativas }\end{array}$ & $\begin{array}{c}77,95 \text { ha } \\
(4,4 \%)\end{array}$ & $\begin{array}{c}11,86 \text { ha } \\
(0,7 \%)\end{array}$ & $\begin{array}{c}318,84 \text { ha } \\
(21,5 \%)\end{array}$ & $\begin{array}{l}4,07 \text { ha } \\
(0,3 \%)\end{array}$ & $\begin{array}{c}43,84 \text { ha } \\
(2,1 \%)\end{array}$ & $\begin{array}{l}5,44 \text { ha } \\
(0,3 \%)\end{array}$ \\
\hline & $\begin{array}{l}\text { Redes viarias, ferroviarias y } \\
\text { terrenos asociados }\end{array}$ & $\begin{array}{l}\text { O ha } \\
(0 \%)\end{array}$ & $\begin{array}{l}\text { 7,69 ha } \\
(0,4 \%)\end{array}$ & $\begin{array}{l}\text { Oha } \\
(0 \%)\end{array}$ & $\begin{array}{c}53,28 \text { ha } \\
(3,6 \%)\end{array}$ & $\begin{array}{l}\text { O ha } \\
(0 \%)\end{array}$ & $\begin{array}{c}38,41 \mathrm{ha} \\
(1,8 \%)\end{array}$ \\
\hline & Zonas de extracción minera & $\begin{array}{l}\text { O ha } \\
(0 \%)\end{array}$ & $\begin{array}{c}17,67 \text { ha } \\
(1,0 \%)\end{array}$ & $\begin{array}{c}10,63 \text { ha } \\
(0,7 \%)\end{array}$ & $\begin{array}{c}22,35 \text { ha } \\
(1,5 \%)\end{array}$ & $\begin{array}{l}\text { O ha } \\
(0 \%)\end{array}$ & $\begin{array}{l}\text { O ha } \\
(0 \%)\end{array}$ \\
\hline & Zonas en construcción & $\begin{array}{c}31,58 \text { ha } \\
(1,8 \%)\end{array}$ & $\begin{array}{c}20,12 \text { ha } \\
(1,1 \%)\end{array}$ & $\begin{array}{c}121,76 \text { ha } \\
(8,2 \%)\end{array}$ & $\begin{array}{l}15,29 \text { ha } \\
(1,0 \%)\end{array}$ & $\begin{array}{c}222,47 \text { ha } \\
(10,5 \%)\end{array}$ & $\begin{array}{c}52,57 \mathrm{ha} \\
(2,5 \%)\end{array}$ \\
\hline & $\begin{array}{l}\text { Zonas industriales o } \\
\text { comerciales }\end{array}$ & $\begin{array}{c}0,55 \text { ha } \\
(0 \%)\end{array}$ & $\begin{array}{c}94,32 \text { ha } \\
(5,3 \%)\end{array}$ & $\begin{array}{l}2,12 \text { ha } \\
(0,1 \%)\end{array}$ & $\begin{array}{c}61,45 \text { ha } \\
(4,1 \%)\end{array}$ & $\begin{array}{c}50,63 \text { ha } \\
(2,4 \%)\end{array}$ & $\begin{array}{c}43,67 \text { ha } \\
(2,1 \%)\end{array}$ \\
\hline & Zonas portuarias & $\begin{array}{l}0 \text { ha } \\
\text { (0 \%) }\end{array}$ & $\begin{array}{l}11,61 \text { ha } \\
(0,6 \%)\end{array}$ & $\begin{array}{l}\text { Oha } \\
(0 \%)\end{array}$ & $\begin{array}{l}0 \text { ha } \\
(0 \%)\end{array}$ & $\begin{array}{l}0 \text { ha } \\
\text { (0 \%) }\end{array}$ & $\begin{array}{l}11,61 \text { ha } \\
(0,6 \%)\end{array}$ \\
\hline & Zonas verdes urbanas & $\begin{array}{l}\text { Oha } \\
(0 \%)\end{array}$ & $\begin{array}{l}\text { Oha } \\
(0 \%)\end{array}$ & $\begin{array}{l}\text { Oha } \\
(0 \%)\end{array}$ & $\begin{array}{l}0 \text { ha } \\
(0 \%)\end{array}$ & $\begin{array}{l}\text { Oha } \\
(0 \%)\end{array}$ & $\begin{array}{c}11,89 \text { ha } \\
(0,6 \%)\end{array}$ \\
\hline
\end{tabular}

Fuente: elaboración propia a partir de Corine Land Cover 2006 
En el caso del turismo vacacional en Dénia (Figura 6), las áreas turísticas se construyen fundamentalmente a partir de tejido urbano discontinuo (71,4\% del total de suelo ocupado). Únicamente el uso deportivo y recreativo destaca en las áreas turísticas (4,4\%) por encima del porcentaje que, de este mismo uso, se construye fuera del espacio turístico ya que tan sólo un 0,7\% aparece vinculado a la ciudad convencional. De este modo, en Dénia se configuran las áreas turísticas como espacios fundamentalmente residenciales con mínimos usos deportivos o recreativos. El tejido urbano se localiza fundamentalmente en la primera línea litoral, de modo que los crecimientos turísticos discontinuos se construyen a ambos lados del núcleo fundacional de la ciudad, al norte y al sur, en contacto con las playas de arena o los puntos de acceso al mar entre las rocas. También existe un importante crecimiento hacia el interior de carácter discontinuo, motivado por la escarpada orografía de la ladera de El Montgó. De esta manera, los asentamientos turísticos se adaptan a la pendiente.

Aunque los asentamientos descritos son fundamentalmente discontinuos, deben matizarse las diferencias que existen entre aquellos que se localizan en la primera línea de costa y los ubicados al interior en relación con su organización espacial y la variedad de alojamiento turístico.

En primer lugar, las tipologías edificatorias junto a la costa combinan el bloque de apartamentos con la vivienda unifamiliar en sus distintas modalidades - en hilera, pareadas o aisladas- para construir un espacio urbano en el que el espacio público tiene escasa relevancia como lugar de encuentro. Únicamente los paseos marítimos y las playas constituyen lugares donde desarrollar la vida social al margen del espacio libre dentro de las parcelas de alojamiento, pues tanto los bloques de apartamentos como las viviendas unifamiliares están permanentemente asociados a espacios libres de gestión privada desde los que disfrutar del clima y de la naturaleza.

En segundo lugar, los alojamientos turísticos en establecimientos reglados que completan la oferta se disponen de distinta forma en la costa y el interior. Aunque partimos de áreas fundamentalmente residenciales, en las áreas turísticas situadas en costa se construyen hoteles, al contrario de lo que sucede en el interior, donde únicamente existen un par de establecimientos hoteleros. Esta situación contrasta con la ciudad tradicional, pues su tejido continuo permite alojar una mayor proporción de hoteles que en las áreas turísticas.

Por tanto, en el caso del turismo vacacional que caracteriza a Dénia, destaca la construcción de tejido turístico a partir de vivienda de segunda residencia que se mezcla con otros tipos de alojamiento -hoteles, apartahoteles, camping, etc.-. Además, no se utilizan localizaciones que exclusivamente tienen buen acceso a las playas, sino que también destacan los desarrollos urbanos en el interior, con peor acceso a las playas pero espectaculares vistas panorámicas, donde las viviendas unifamiliares aisladas alojan, también, turismo. 
Figura 6. Tipos de ocupación de suelo y delimitación de áreas turísticas en Dénia

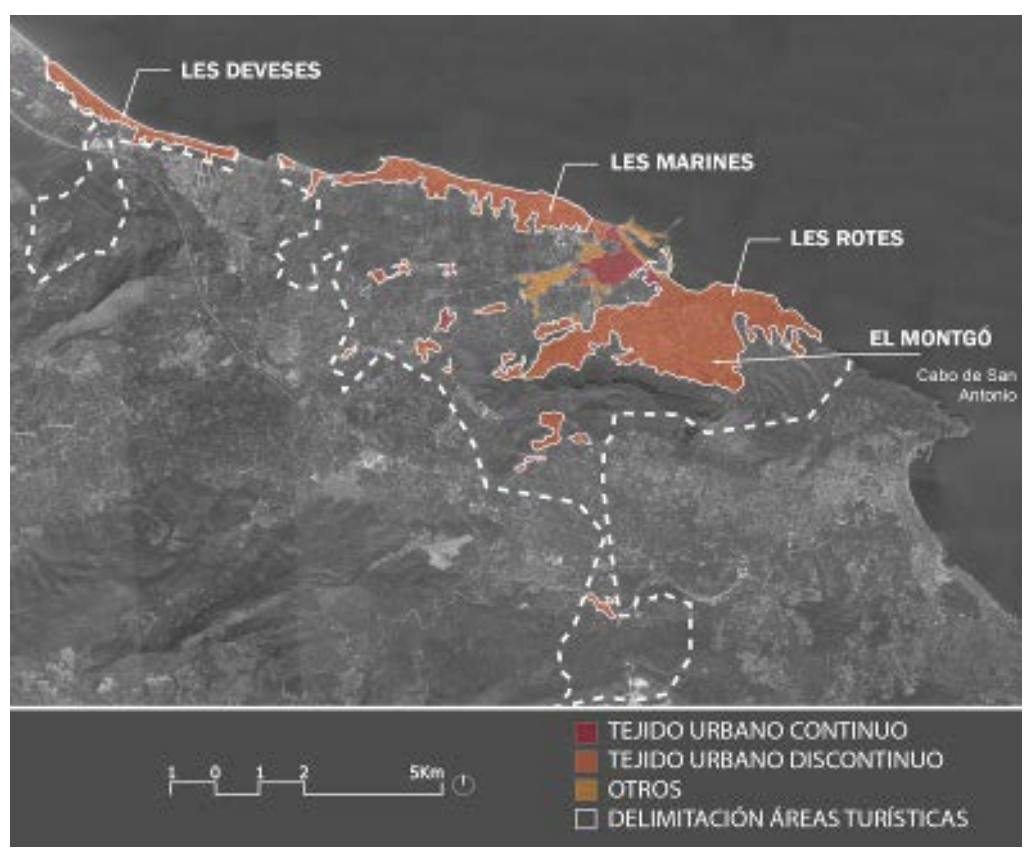

Fuente: elaboración propia

En el caso del turismo de masas en Benidorm existe un cierto equilibrio entre el uso residencial continuo, discontinuo y el uso deportivo y recreativo, motivado por la estrategia de diversificación de la oferta turística del municipio (Figura 7).

Figura 7. Tipos de ocupación de suelo y delimitación de áreas turísticas en Benidorm

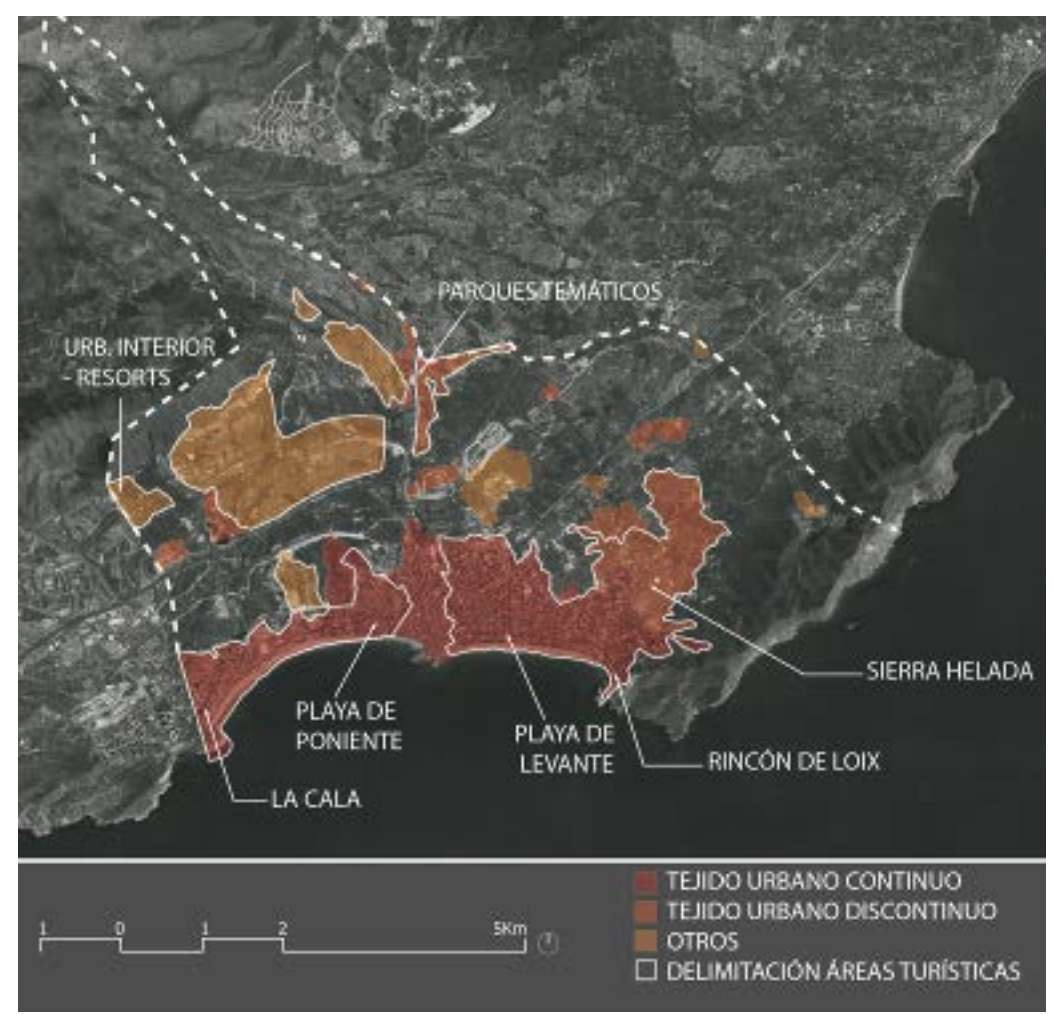

Fuente: elaboración propia 
Desde prácticamente el inicio de la actividad turística, Benidorm apuesta en su planeamiento por una ocupación del territorio concentrada junto al frente marítimo, liberando el suelo interior del término municipal (Martí y Oliva, 2002). El tejido continuo caracteriza la estructura urbano-turística original de Benidorm con el desarrollo de los ensanches de Levante y Poniente donde se desarrolla la actividad en un escenario de marcado carácter urbano. Las edificaciones en altura de ambos ensanches permiten alojar en poca superficie a un gran número de visitantes; precisamente, la tipología de torre es aquella que caracteriza la estrategia de ocupación de suelo del modelo turístico de Benidorm y, también, su imagen más difundida (Figura 8).

Sin embargo, en los años 90, comienzan a desarrollarse bolsas de suelo de tejido urbano discontinuo que se localizan en el interior del término municipal. Este tipo de desarrollo, fundamentalmente residencial, se construye en continuidad con los municipios colindantes para ofrecer variedad de alojamiento que complemente al hotelero y a los apartamentos del espacio urbano original.

La configuración de espacios libres en estas urbanizaciones residenciales es la propia de las tipologías de vivienda unifamiliar en sus formas aisladas o agrupadas en comunidad. De igual manera, se localizan, cerca del continuo urbano, parques acuáticos y de ocio; como es el caso de los complejos de Aqualandia y Mundomar.

Recientemente, se realiza una importante revisión de la oferta turística del municipio y, con la intención de procurar una mayor variedad de formas de alojamiento y ocio se construyen: un campo de golf (Villaitana), un resort de lujo (Asia Gardens) y varios parques temáticos (Terra Mítica y Terra Natura). Todos ellos ocupan una importante cantidad de suelo en el interior del término municipal y, aunque desvinculadas del continuo urbano, se localizan en posiciones convenientes para la buena conexión territorial.

Por tanto, con el objetivo de mantener Benidorm como destino turístico de primer orden, el incremento y la diversificación de la oferta ha generado nuevos espacios turísticos que hacen que la estructura de ocupación de suelo de carácter continuo con la que se identificaba la ciudad en su origen se haya transformado. Estos cambios han dado lugar a una ocupación del suelo muy diferente en la que, prácticamente, se ocupan fracciones equivalentes de superficie para el uso residencial continuo, discontinuo y el deportivo-recreativo.

Por último, en el caso del turismo residencial de Torrevieja, la zona preferida para la ocupación turística se localizó inicialmente junto a la línea costera, ocupando una amplia franja. Más tarde, una vez consumido prácticamente todo el suelo litoral, se comenzó a ocupar el espacio próximo al Parque Natural de las lagunas de Torrevieja y La Mata, colmatando prácticamente todo el espacio que queda entre ambas lagunas fuera del límite del parque natural, situando en este ámbito una importante urbanización turístico-residencial (Figura 9). 
Figura 8. Imagen del skyline de Benidorm caracterizado por sus edificios en altura

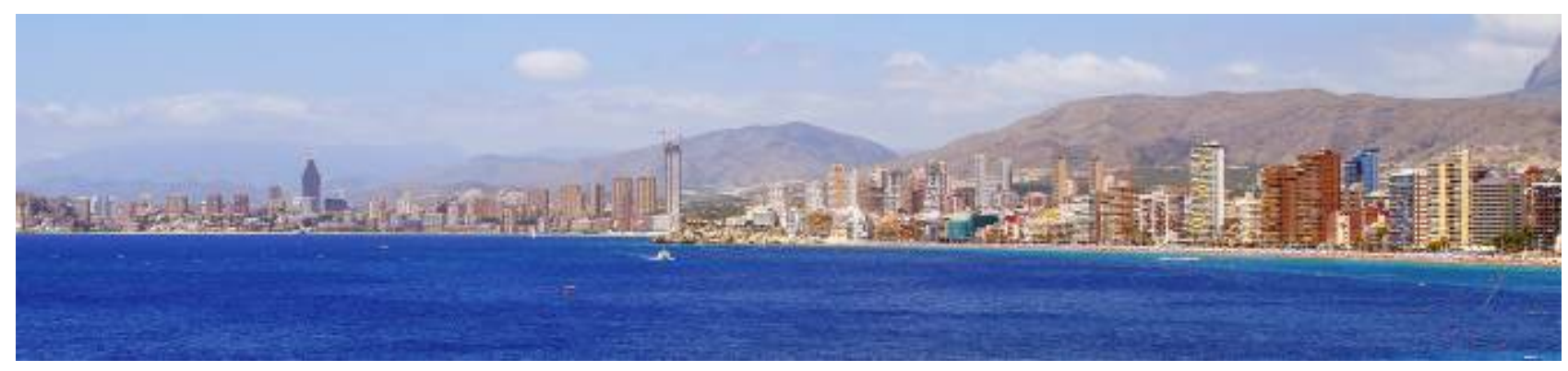

Fuente: elaboración propia

Figura 9. Tipos de ocupación de suelo y delimitación de áreas turísticas en Torrevieja

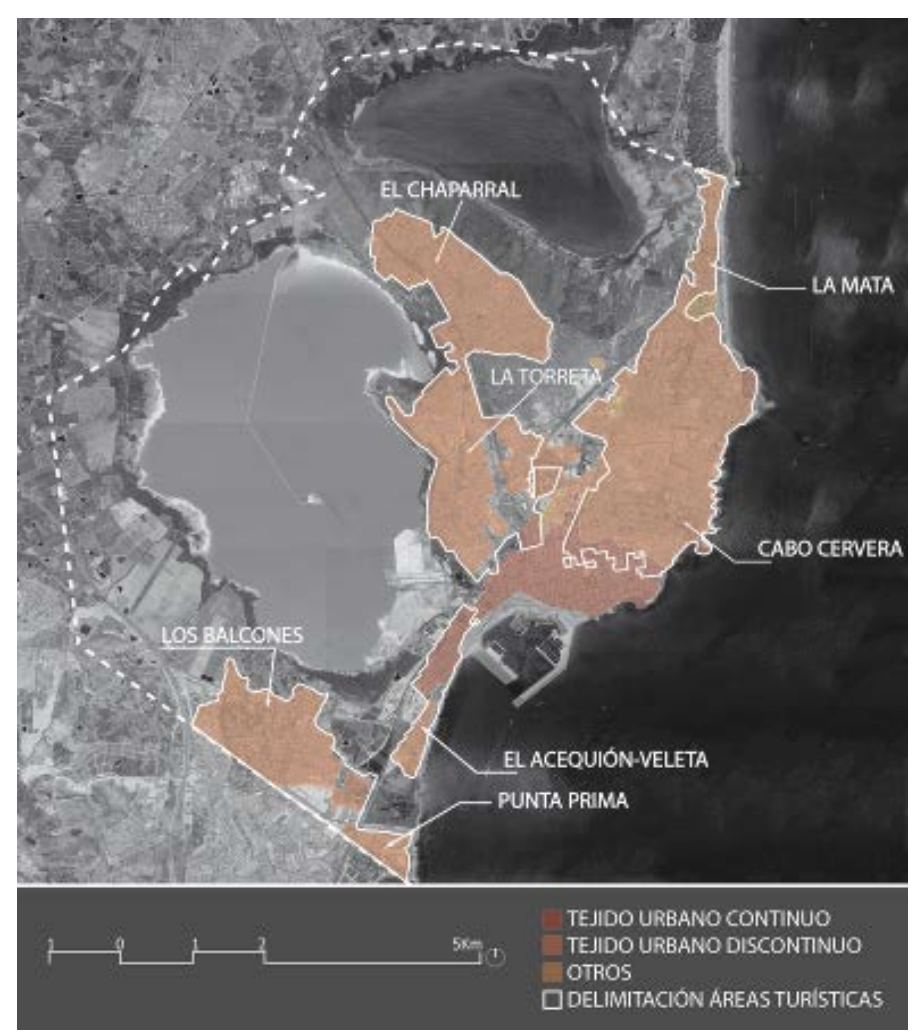

Fuente: elaboración propia

Estos desarrollos urbanos tienen un marcado carácter discontinuo de uso residencial estacional, a la vista del dato de viviendas de segunda residencia y la escasa localización de cualquier otro tipo de alojamiento (Tabla 3). Igualmente destaca la clasificación de "zonas en construcción" que el proyecto Corine Land Cover 2006 cuantifica con una superficie en torno al $10 \%$ en Torrevieja y que se localiza en continuidad con el uso de tejido urbano discontinuo. Este dato invita a deducir que la producción de suelo con fines turísticos en el municipio tiende a seguir la estrategia ya consolidada, aunque sí es cierto que, recientemente, los esfuerzos en cuanto a la cualificación del destino han estado concentrados en la construcción de servicios y espacios para el ocio y la cultura. 
Por tanto, en este caso, la producción de suelo urbano-turístico se centra en ocupar suelos con uso residencial de manera discontinua, utilizando fundamentalmente tipologías de vivienda unifamiliar aislada, pareada o en hilera. Asimismo, los espacios libres que se generan en estas áreas son de gestión y uso privado en su gran mayoría.

\section{Conclusiones}

La realidad de gran parte de las zonas costeras de la Costa Blanca, en las que el turismo constituye la base de sus economías, refleja que la actividad turística requiere de importantes superficies de territorio para su desarrollo. Además, el alto grado de especialización que demanda la actividad, para competir dentro de un sector cada día más exigente, tiene efectos positivos y negativos sobre el territorio.

En este estudio, en el que se ponen en relación las estrategias de ocupación de suelo y el tipo de actividad turística, se observa cómo la especialización genera externalidades negativas en cuanto al consumo de suelo. Sin embargo, la combinación de distintos tipos de turismo en el ámbito territorial de la Costa Blanca, cubriendo distintos segmentos de la demanda, refuerza la sostenibilidad de la industria turística a largo plazo.

Las distintas formas de consumo de suelo pueden asociarse a las cualidades que los distintos tipos de turismo desarrollan en cada municipio. Se identifica cómo, por una parte, el modelo turístico residencial se aloja en estructuras de ocupación extensiva del territorio y, por otra parte, los modelos dinámicos o de rotación encuentran soporte en estructuras urbanas compactas. De este modo, puede afirmarse que existe un vínculo entre las formas de crecimiento urbano de un asentamiento turístico y el tipo de turismo que aloja. Por tanto, resulta conveniente conocer las pautas territoriales y urbanas con que se han construido los crecimientos turísticos actuales para realizar una adecuada planificación de las estrategias de ocupación y diseño del espacio urbanoturístico a futuro.

En relación con los datos obtenidos en los diferentes casos de estudio, que explican las estrategias de ocupación de las áreas turísticas asociadas a diversos tipos de turismo, pueden destacarse algunas cuestiones relevantes.

En primer lugar, los valores de ocupación de suelo respecto a la superficie del término municipal son elevados y particularmente altos para los espacios urbanos en los que se desarrollan modelos turísticos residenciales. Además, el análisis del grado de ocupación de suelo resulta especialmente significativo en espacios turísticos litorales al observar que la mayor parte del suelo ocupado corresponde a espacios urbano-turísticos creados específicamente para el alojamiento de la actividad. 
Se puede considerar también que, a partir de los casos estudiados, los factores que influyen en un mayor consumo de suelo son dos. Por una parte, la alta demanda de tipologías unifamiliares con espacios libres asociados que se produce en el tipo residencial y vacacional y, por otra parte, los usos deportivos y recreativos de campos de golf y parques temáticos. Sin embargo, aunque puedan discutirse algunas cuestiones en relación con las adecuadas formas de implementación de ambos en los modelos turísticos, sí es cierto que, frecuentemente, los primeros se localizan en ubicaciones de alto valor paisajístico y ecológico, como sucede en Dénia y Torrevieja, mientras que los segundos, como en Benidorm, se plantean en espacios que a priori resultaban de escaso interés turístico pero que mantienen una estratégica localización territorial en conexión con importantes infraestructuras viarias.

En segundo lugar, existen grandes diferencias entre las estrategias de ocupación para el alojamiento del turismo de masas y el utilizado por el turismo residencial en la Costa Blanca. El turismo de masas, en Benidorm, utiliza las tipologías de torre y bloque en la franja próxima a la costa liberando suelo para otros usos en el interior. Además, la función hotelera, comercial y de ocio de su espacio urbano-turístico complementan la edificación residencial, influyendo directamente en el desarrollo de un modelo más compacto, y también, más complejo; una condición urbana que favorece la diversidad de funciones, aunque manteniendo una alta especialización en torno al ocio.

Sin embargo, por su parte, el turismo residencial, en Torrevieja, hace uso de una estrategia de ocupación de densidad media-baja para su desarrollo. Los espacios urbano-turísticos generados son los propios de las estructuras suburbanas monofuncionales en los que la especialización no se produce en torno a las actividades del ocio, sino alrededor de enclaves residenciales singulares donde disfrutar del buen clima y de la proximidad a entornos naturales de gran valor (SerranoEstrada et al., 2016).

$Y$, en el caso del turismo vacacional, en Dénia, se combina cierta variedad tipológica que permite el desarrollo de estructuras espaciales que, si bien son próximas a la estructura urbana, mantienen un alto grado de integración con el entorno natural, favoreciendo la amortiguación del gran impacto paisajístico que las bolsas de alojamiento propias del tejido urbano discontinuo suelen tener.

En tercer lugar, es muy destacable que las estrategias de ocupación de los modelos vacacional y residencial se construyen a partir de una escasa existencia de espacio público ciudadano y se observa un incremento importante de la cantidad de espacio libre privado -independientemente de su uso comunitario o individual- en comparación con la configuración de los tejidos urbanos convencionales.

Por todo lo expuesto, se identifica el turismo de masas con las morfologías de tejido urbano continuo y, el turismo residencial y vacacional con las morfologías de tejido urbano discontinuo. En 
este sentido es necesario insistir en los efectos negativos derivados del uso extensivo del tejido urbano discontinuo en la ocupación cercana a parajes de valor paisajístico y ecológico. Así, se constata la contradicción existente entre cómo el disfrute de aquellos parajes naturales que constituyen el principal atractivo turístico se produce poniendo en riesgo el valor de estos mismos espacios por la presión urbanizadora.

Por tanto, se consideran más eficientes, en cuanto a su modo de ocupación, las estructuras turísticas que sean capaces alojar una mayor cantidad de población turística en un espacio urbano reducido de configuración continua, así como, con una adecuada proporción de espacio libre y actividades específicas del ocio. Por lo cual, son más eficientes en cuanto a esta consideración las tipologías que, en Benidorm, se utilizan para alojar al turismo de masas. En este sentido, a pesar de que no pueda considerarse como eficiente la ocupación sobre la que se desarrolla el turismo residencial con el uso de tejido discontinuo, serán un tanto más respetuosos con el medio ambiente los modelos de ocupación que, como en el caso de Denia, combinan la actividad residencial con los modos de alojamiento rotacional típicamente vacacionales dado que producen un espacio turístico híbrido entre el escenario de carácter urbano y el paisaje natural.

En definitiva, atender adecuadamente a las diferentes estrategias de ocupación de la actividad turística supone entender la demanda de un mercado diverso y exigente, así como planificar el territorio de acuerdo, no sólo a dicha demanda, sino al interés del desarrollo local y de la planificación urbana.

Estratégicamente, los nuevos planes urbanísticos deberán procurar la construcción de asentamientos que sigan siendo atractivos para el turismo y también adecuados para el desarrollo futuro de las ciudades y territorios del complejo espacio litoral. 


\section{Bibliografía}

Agència Valenciana del Turisme (2014). Winsitur. Recuperado el 5 enero 2015, de http://www.turisme.gva.es/opencms/opencms/turisme/es/contents/touristinfo/winsitur.html Baños, C. J. (1999). Modelos turísticos locales: análisis comparado de dos destinos de la Costa Blanca. Investigaciones Geográficas, 21, 35-58.

Burriel de Orueta, E. (2008). La "década prodigiosa" del urbanismo español (1997-2006). Scripta Nova, XII, 270(64). Recuperado de http://www.ub.edu/geocrit/sn/sn-270/sn-270-64.htm

Consellería de Medio Ambiente, Urbanismo y Vivienda (2011). Estrategia Territorial de la Comunitat Valenciana. Decreto 1/2011, de 13 de enero.

Dirección General del Catastro. (2015). ¿Qué es el catastro? Recuperado el 5 octubre 2015, de http://www.catastro.minhap.gob.es/esp/fags.asp

Domínguez, L., Martí, P., y Nolasco-Cirugeda, A. (2016). Turismo residencial de noreuropeos en la Costa Blanca: su manifestación territorial y estudio de casos representativos. Scripta Nova, XX. Recuperado de http://www.ub.edu/geocrit/sn/sn-547.pdf

European Environment Agency (2006). Corine Land Cover 2006. Recuperado de http://www.ign.es/ign/layoutln/corineLandCover.do

Gaja, F. (2008). El "tsunami urbanizador" en el litoral mediterráneo. El ciclo de hiperproducción inmobiliaria 1996-2006. Scripta Nova, XII, 270(66). Recuperado de http://www.ub.edu/geocrit/sn/sn-270/sn-270-66.htm

García-Mayor, C. (2017). Invariantes en la evolución e identidad territorial del paisaje de huerta tradicional de la Vega Baja del río Segura: 1929-2010. Boletín de la Asociación de Geógrafos Españoles, 73, 369-388. doi: 10.21138/bage.2422

Hernández, M. (2013). Análisis de los procesos de transformación territorial en la provincia de Alicante (1985-2011) y su incidencia en el recurso hídrico a través del estudio bibliográfico. Documents d'Anàlisi Geogràfica, 59(1), 105-136.

Huete, R. (2009). Turistas que llegan para quedarse: una explicación sociológica sobre la movilidad residencial. Alicante: Publicaciones Universidad de Alicante.

Huete, R. (2016). La vertiente residencial del turismo. Canelobre, 66, 125-133.

Huete, R., y Mantecón, A. (2011). Más allá del turismo: Movilidad Residencial europea y nuevos núcleos urbanos. Boletín de la Asociación de Geógrafos Españoles, 56, 111-128. 
INE (Instituto Nacional de Estadística) (2013a). Encuesta de ocupación hotelera. Pernoctaciones por puntos turísticos $y$ meses (demanda). Recuperado de http://www.ine.es/jaxi/menu.do?type=pcaxis\&path=\%2F+11\%2Fe162eoh\&file=inebase

INE (Instituto Nacional de Estadística) (2013b). Censo de población y vivienda 2011. Recuperado de http://www.ine.es/censos2011_datos/cen11_datos_resultados.htm

Instituto Geográfico Nacional y Ministerio de Fomento. (2015). Plan Nacional de Ortofotografía Aérea (PNOA). Recuperado de http://www.ign.es/wms-inspire/pnoa$\underline{\text { ma? service }=\text { WMS\&request }=\text { getCapabilities }}$

Ivars, J. A., y Menor, M. (2008). El Impacto de las compañías aéreas de bajo coste en la actividad turística del área de influencia del aeropuerto de Alicante. Estudios Turísticos, 175-176, 89-104. Recuperado de http://www.iet.tourspain.es:20000/img-iet/Revistas/RET-175-176-2008-pag89104-104438.pdf

Ivars, J. A., Rodríguez, I., y Vera, J. F. (2013). The evolution of mass tourism destinations: New approaches beyond deterministic models in Benidorm (Spain). Tourism Management, 34, 184-195. doi: 10.1016/j.tourman.2012.04.009

Jiménez, L. (2006). Cambios de Ocupación del Suelo en España. Implicaciones para la sostenibilidad. Madrid: Observatorio de la Sostenibilidad en España. Recuperado de http://www.sostenibilidad-es.org/sites/default/files/Informes/tematicos/suelo/suelo-esp.pdf Mantecón, A. (2008). La experiencia del turismo. Un estudio sociológico sobre el proceso turísticoresidencial. Barcelona: Icaria.

Mantecón, A. (2016). La dimensión social del turismo. Canelobre, 66, 157-165.

Martí, P., Nolasco-Cirugeda, A., y Serrano-Estrada, L. (2017a). Assessment tools for urban sustainability policies in Spanish Mediterranean tourist areas. Land Use Policy, 67, 625-639. Recuperado de http://doi.org/10.1016/j.landusepol.2017.06.015

Martí, P., Serrano-Estrada, L., y Nolasco-Cirugeda, A. (2017b). Using locative social media and urban cartographies to identify and locate successful urban plazas. Cities, 64, 66-78. doi: 10.1016/j.cities.2017.02.007

Martí, P., y Nolasco-Cirugeda, A. (2016). El urbanismo y la urbanización del turismo. Canelobre, $66,147-155$

Martí, P., y Nolasco-Cirugeda, A. (2012). Un caso paradigmático de sprawl: la costa de la provincia de Alicante. ACE: Architecture, City and Environment, 173-198. Recuperado de https://upcommons.upc.edu/bitstream/handle/2099/12646/ACE_20_SE_25.pdf 
Martí, P., y Oliva, J. (2002). Algunas intervenciones en la costa mediterránea de Alicante: tres propuestas, tres ideologías, tres actitudes. En Arquitectura moderna y turismo: 1925-1965 (pp. 225-230). Actas del IV Congreso Fundación DOCOMOMO Ibérico. Valencia, 6-8 de noviembre de 2003. Barcelona: Fundación Docomomo Ibérico.

Martínez-Medina, A. (2016). Arquitectura del boom turístico (1953-1979). Canelobre, 66, 167-185. Membrado, J. C. (2015). Migración residencial y urbanismo expansivo en el Mediterráneo español. Cuadernos de Turismo, 35, 259-285. doi: 10.6018/turismo.35.221611

Pié, R. (2013). Las arquitecturas del turismo: las piezas mínimas. En R. Pié y C. Rosa (Eds.), Turismo Líquido (pp. 14-37). Barcelona: Instituto Hábitat Turismo y Territorio a través de Digital Politécnica (UPC). Universidad Politécnica de Catalunya y Universidad de Málaga.

Pié, R. y Rosa, C. (Eds.) (2013). Turismo Líquido. Barcelona: Instituto Hábitat Turismo y Territorio a través de Digital Politécnica (UPC). Universidad Politécnica de Catalunya y Universidad de Málaga.

Rueda, S. (1997). La ciudad compacta y diversa frente a la conurbación difusa. En Ciudades para un futuro más sostenible. Recuperado de http://habitat.aq.upm.es/cs/p2/a009.html

Serrano-Estrada, L., Marti, P., y Nolasco-Cirugeda, A. (2016). Comparing Two Residential Suburban Areas in the Costa Blanca, Spain. Articulo, Journal of Urban Research, 13. Recuperado de https://articulo.revues.org/2935

Steenmans, C. (Dir.) (2000). CORINE Land Cover Technical Guide-Addendum 2000. Copenhague: European Environment Agency. Recuperado de http://image2000.jrc.ec.europa.eu/reports/corine_tech_guide_add.pdf

Vera, J. F., Ivars, J. A., y Celdrán, M. A. (2016). Evolución y metabolismo de un lugar transformado por el turismo de masas. Una interpretación del modelo turístico de Torrevieja desde la teoría de la dependencia de la trayectoria (Path Dependence). En Libro Homenaje al Profesor Alfredo Morales Gil, 705-736. doi: 10.14198/LibroHomenajeAlfredoMorales2016-32

Vera, J. F. (1987). Turismo y urbanización en el litoral alicantino. Alicante: Instituto de Estudios Juan Gil-Albert.

Vera, J. F. (2005). El auge de la función residencial en destinos turísticos del litoral mediterráneo: entre el crecimiento y la renovación. Papers de Turisme, 37-38, 95-114.

Vera, J. F., Marchena, M. J., Anton-Clavé, S., y López-Palomeque, F. (2011). Análisis territorial del turismo y planificación de destinos turísticos. Valencia: Tirant lo Blanch.

Vera, J. F., y Díez, D. (2016). Espacios y destinos turísticos. Canelobre, 66, 85-97.

Vera, J. F., e Ivars, J. A. (2009). Spread of Low-Cost Carriers: Tourism and Regional Policy Effects in Spain. Regional Studies, 43 (4), 559-570. doi: 10.1080/00343400701874164 
Vera, J. F., Rodríguez, I., y Capdepón, M. (2011). Reestructuración y competitividad en destinos maduros de sol y playa: la renovación de la planta hotelera de Benidorm. En Renovación de Destinos Turísticos Consolidados (pp. 844-867). Actas del XIII Congreso Internacional de Turismo Universidad y Empresa. Castellón, 6-8 de mayo de 2010. doi: 10.13140/2.1.4863.2004 